\title{
IGLESIA Y ASAMBLEA CONSTITUYENTE ${ }^{\star}$
}

Luciano Bellini Fedozzi, sdb

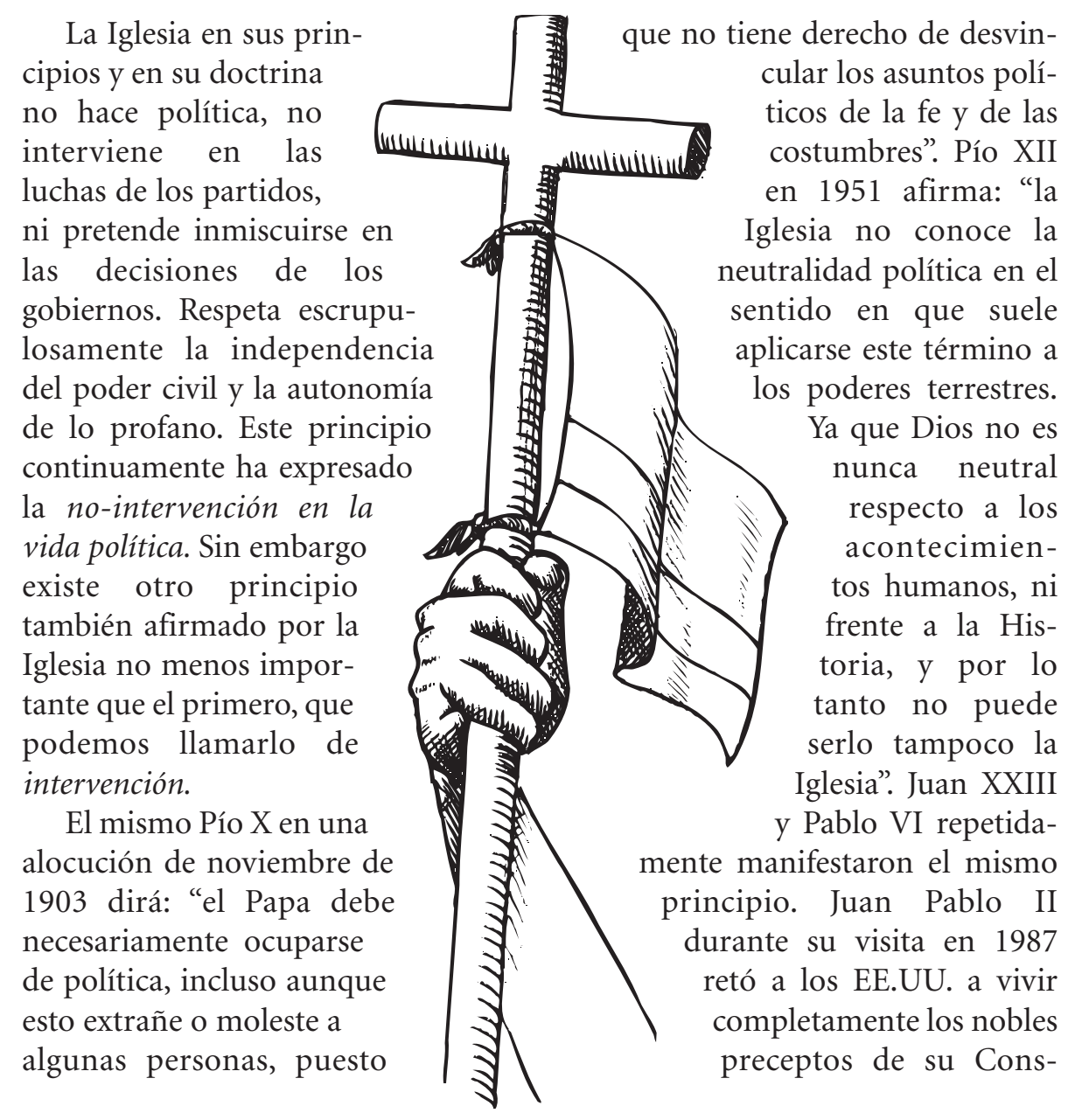

* Ponencia del P. Luciano Bellini Fedozzi, Rector de la Universidad Politécnica Salesiana en el Foro "Iglesia y Asamblea Constituyente",organizado por la Comisión Política de la UPS Sede Quito, 24 de octubre de 2007 
Luciano Bellinni Fedozzi, sdb.

titución respetando la dignidad de todo ser humano: "por esta misma razón, América, tu más profunda identidad y verdadero carácter como nación se revela en la postura que tomes como nación hacia la persona humana. La prueba máxima de tu grandeza está en la forma que trates a cada ser humano, pero especialmente a los más débiles y más indefensos".

Hay dos principios contradictorios en la postura de la Iglesia, el no pero si. La Iglesia no interviene en la política, pero si lo hace y debe hacerlo, cada vez que está comprometido el mensaje evangélico, porque la fe no abarca solo la dimensión espiritual del hombre sino también la dimensión temporal. La Iglesia debe intervenir cuando se trate de defender la moral cristiana, la libertad de la persona humana, la paz y la justicia de los pueblos. La Iglesia desde su postura siempre ha intervenido en los momentos críticos de la existencia de los pueblos, en defensa del derecho y de la justicia, esto le ha provocado no pocas persecuciones y martirios. Lo hemos visto muy bien en América Latina, desde 1521 con Pedro de Córdoba, misionero en República Dominicana, hasta el 24 de marzo de 1980 Oscar Arnulfo Romero en el Salvador y todavía posteriormente en el mismo Salvador Ignacio Ellacuría y sus compañeros asesinados por defender los pobres y la justicia, los mártires en América Latina se cuentan por centenares, sacerdotes, religiosos, religiosas, laicos.

\section{El rol del laico católico en la política}

En la Encíclica Gaudium et Spes encontramos expresado el criterio de que todo ciudadano tiene responsabilidad social. La solución a la corrupción y otros abusos no es abandonar la política sino, al contrario, participar más en ella. Los cristianos deben ser sal que preserva de la corrupción...sin dejarse seducir por las pasiones o intereses. En uno de los discursos de Benedicto XVI, insiste en que la Iglesia enseña fundamentos sólidos para poder discernir y actuar en lo social y que la persona es el centro de toda acción y por lo tanto se debe fomentar el respeto de los derechos humanos, el compromiso por la paz y la promoción de la justicia para todos. El mismo Papa cuando todavía cardenal, afirmaba que hay que evitar la teocracia de la política. "La justa profundidad de la política excluye la teocracia".

El laico inmerso en la política debe conocer los principios fundamentales de la Doctrina Social de la 
Iglesia, tiene que buscar la verdad. Evitar la demagogia utilizando el sufrimiento ajeno, la raza, los pobres, la libertad, etc. Debe tener claro que el principio maquiavélico no tiene justificación ninguna. "El fin no justifica los medios". No se puede utilizar un medio perverso para conseguir un bien. Por esta razón habrá que condenar el terrorismo, de donde sea que venga, el aborto, el secuestro, la mentira y la difamación. El bien común debe estar por encima de todo interés personal, no se deben violar los derechos naturales de ninguna persona. No se puede apoyar a quien va en contra de la ley natural.

Los Obispos de EEUU en 1995 declararon: "En la tradición católica, la ciudadanía es una virtud y la participación en el proceso político es una obligación". El político cristiano tiene que dar testimonio de su fe y ser coherente con sus principios. Debe tener como preocupación esencial la justicia, una que no se contente con dar a cada uno lo suyo sino que debe tender a crear entre los ciudadanos condiciones de igualdad en las oportunidades, y por lo tanto deberán favorecer a aquellos que por sus condiciones tienen el peligro de quedar relegados y ocupar siempre los últimos puestos en la sociedad. Tiene también que promover la solidaridad que vaya por encima de la desmesurada búsqueda de las riquezas de uno produciendo la pobreza en otros.

En el Jubileo del año 2000, precisamente el 4 de noviembre, el Papa Juan Pablo II así se dirigía a los políticos reunidos en Roma: "Quisiera ahora, en particular, dirigir una palabra a aquellos de ustedes que tienen la delicada misión de formular y aprobar las leyes: una tarea que aproxima el hombre a Dios, supremo Legislador, de cuya ley eterna toda ley recibe en ultima instancia su validez y su fuerza vinculante. A esto se refiere precisamente la afirmación de que la ley positiva no puede contradecir la ley natural, al ser ésta una indicación de las normas primeras y esenciales que regulan la vida moral y, por tanto, expresión de las características, de las exigencias profundas y de los más elevados valores de la persona humana...”. Y todavía continua: "Nosotros los cristianos de este tiempo formidable y maravilloso al mismo tiempo, aun compartiendo los miedos, las incertidumbres y los interrogantes del hombre de hoy, no somos pesimistas sobre el futuro, puesto que tenemos la certeza de que Jesucristo es el Dios de la historia, y porque tenemos en el Evangelio la luz que ilumina nuestro camino, incluso en los momentos difíciles y oscuros". 
Luciano Bellinni Fedozzi, sdb.

\section{El pensamiento de los obispos del Ecuador}

En una nota de la agencia católica Aciprensa se recoge el pensamiento de nuestros obispos del Ecuador. "Nuestro país vive hoy una realidad marcada por el deseo de grandes cambios positivos que afecten profundamente la vida de la Nación para bien de todos. Contemplamos con dolor los rostros de nuestros hermanos que sufren, pobres, desempleados, emigrantes, desplazados que buscan sobrevivir con una economía informal; niños y niñas sometidos al trabajo y la prostitución infantil, así como niños víctimas del aborto. Sufrimos con los que sufren soledad y se ven excluidos de la convivencia familiar y social".

Con esta premisa, nuestros Obispos piden a la Asamblea Constituyente:

- Dignidad de la persona humana, como imagen de Dios con su yo insustituible.

- Educación, centrada en la persona humana, y que el Estado garantice el derecho que tienen los padres de familia a escoger libremente la educación de sus hijos.

- Familia-vida: el Estado garantice y proteja la vida humana, como derecho primario inalienable de toda persona; así como a la familia, formada por un hombre y una mujer, origen de la vida y célula fundamental de toda sociedad.

- Corrupción y pobreza: el Estado garantice la creación de los elementos necesarios para que los ciudadanos, las funciones del Poder Público y los órganos de control impidan su corrupción en todas sus formas.

- Estructuras del Estado, sometidas a reformas que promuevan el robustecimiento de la unidad nacional y de una democracia real y participativa basada en la persona.

\section{En el proyecto de Dios el silen- cio es pecado}

El primer ejemplo en la historia, de intervención en la vida del hombre, es precisamente el de Dios. Dios frente a la explotación no queda insensible y oye el clamor de su pueblo. Se compadece y suscita hombres capaces de llevar un proceso de liberación, dándoles el valor de enfrentarse con el enemigo, el opresor. $\mathrm{He}$ aquí el primer ejemplo de gran libertador Moisés. "Moisés se cubrió el rostro, porque temía mirar a Dios. El 
Señor siguió diciendo: he visto la opresión de mi pueblo en Egipto, he oído el clamor que le arrancan sus opresores $y$ conozco sus angustias. Voy a bajar para librarlo del poder de los egipcios. Lo sacaré de este país y lo llevaré a una tierra nueva y espaciosa, a una tierra que mana leche y miel...El clamor de los israelitas ha llegado hasta mí. He visto también cómo son oprimidos por los egipcios. Ve, pues; yo te envío al faraón para que saques de Egipto a mi pueblo, a los israelitas." (Ex. 3,7-10)

Toda la historia de salvación del pueblo de Israel está guiada por hombres que el mismo Dios ha suscitado. Después de Moisés tenemos a Josué que recibe el mismo mandato de Dios para conducir al pueblo. Tendremos Jueces, Reyes, grandes hombres y mujeres como Judith, Ester, etc. Hasta llegar a los grandes profetas de Israel, como son Isaías, Jeremías, Ezequiel. El pueblo de Dios va realizando un proceso de consolidación, y como todo pueblo que trata de buscar y afirmar su propia identidad cae en errores y vicios que perjudican al mismo pueblo. Por tanto la opresión ya no viene sólo del exterior sino también del interior, de los que gobiernan al pueblo.

El mismo culto religioso se vuelve sin sentido y puramente exterior, por eso Isaías, inspirado por Dios dirá: "Estoy harto de holocaustos de carneros y de grasa de becerros; detesto la sangre de novillos, corderos $y$ chivos. Cuando vienen ante mí, ¿quién les pide que pisoteen mis atrios? No vuelvan a traer ofrendas vacías, cuya humareda me resulta insoportable... Aborrezco con toda el alma sus lunas nuevas y celebraciones; se me ha vuelto una carga inaguantable. Cuando extienden las manos para orar, aparto mi vista; aunque hagan muchas oraciones, no las escucho, pues tienen las manos manchadas de sangre" (Is. 1,10-15).

De la esclavitud en Egipto, es una lástima pensarlo, el pueblo pasa a una esclavitud en su propia tierra prometida. Donde los opresores ya no son egipcios o de otras tribus cercanas, sino gente del propio pueblo como son los sacerdotes y los gobernantes. La codicia y el abuso de poder lleva al pueblo de Israel a una situación que es muy distinta de estar viviendo en una tierra que "mana leche y miel". Pero Dios amonesta enérgicamente a los que oprimen al pueblo: " Ay de los que dictan leyes opresoras, de los que publican decretos injustos: no hacen justicia a los indefensos, despojan de sus derechos a los pobres de mi pueblo, hacen de las viudas su presa, y despojan a los huérfanos! ¿Qué van a hacer el día del castigo? ¿Cómo se librarán de la catástrofe que les llega de lejos? ¿A quién 
Luciano Bellinni Fedozzi, sdb.

pedirán auxilio? ¿Dónde dejarán sus riquezas? Tendrán que entregarse como prisioneros o caer entre los muertos..." (Is. 10,1-4).

Dios es claro con su pueblo, indicándole el camino que tiene que recorrer si quiere conservar su favor. Por eso Isaías todavía dirá: "El ayuno que yo quiero es este: que sueltes las cadenas injustas, que desates las correas del yugo, que dejes libres a los oprimidos, que acabes con todas las opresiones, que compartas tu pan con el hambriento, que hospedes a los pobres sin techo, que proporciones ropas al desnudo y que no te desentiendas de tus semejantes. Entonces brillará tu luz como la aurora..." (Is. 58,6-8).

Isaías más adelante indicará claramente cuál es la misión del Profeta: "El Espíritu del Señor está sobre mí, porque el Señor me ha ungido. Me ha enviado a dar la buena nueva a los pobres, a sanar a los de corazón destrozado, a proclamar la liberación a los cautivos y a los prisioneros la libertad..." (Is. 61,1-2).

En Jeremías también encontramos una descripción de la acción del Profeta: "Entonces el Señor alargó su mano, tocó mi boca y me dijo: Mira, pongo mis palabras en tu boca: en este dia te doy autoridad sobre naciones $y$ reinos, para arrancar y derribar, para destruir y demoler, para edificar $y$ plantar" (Jr. 1,9-10).
Ezequiel también recibe un llamado especial de Dios: “Te envío a esos hijos que tienen el corazón duro como una piedra. Les hablarás de mi parte, te escuchen o no, pues son un pueblo rebelde, $y$ sabrán que en medio de ellos hay un profeta. Y tú, hijo del hombre, no lo temas ni tengas miedo de sus palabras..." (Ez. 2,4-6). Dios obliga a Ezequiel a hablar, aun sabiendo lo difícil que era presentarse ante el pueblo y ser escuchado. Casi todos los profetas de alguna manera se resisten a la idea de tener que hablar al pueblo para anunciar la voluntad de Dios. Sin embargo todos comprenden las exigencias de Dios y se lanzan protegidos por Espíritu del Señor a denunciar los abusos del pueblo y contra el pueblo, y anunciando el camino que deben seguir.

Juan el Bautista en la misma línea de los profetas sigue llamando la atención del pueblo, para que se acoja a la conversión: "La gente le preguntaba: ¿Qué tenemos que hacer? $Y$ les contestaba: El que tenga dos túnicas, dé una al que no tiene, y el que tenga comida compártala con el que no la tiene. Vinieron también a bautizarse algunos de los que recaudaban impuestos para Roma y le dijeron: Maestro ¿qué tenemos que hacer? Él les respondió: No exijan nada fuera de lo establecido.También los soldados le preguntaban: ¿Y nosotros que tene- 
mos que hacer? Juan les contestó: A nadie extorsionen ni denuncien falsamente, y conténtese con su sueldo..." (Lc. 3,10-14).

La voz más clara de Dios es su mismo Hijo, y no tiene reparo en enviarlo entre los hombres para ser el mensajero del Padre y presentarse como el Padre mismo. En la Sinagoga de Nazaret se da la más grande revelación de parte de Jesús. Leerá el texto de la escritura: "El espiritu del Señor está sobre mí, porque me ha ungido para anunciar la buena noticia a los pobres; me ha enviado a proclamar la liberación a los cautivos, a dar vista a los ciegos, a libertar a los oprimidos y a proclamar un año de gracia del Señor (Sal. 9,1-2)" (Lc. 4,18-19).

$\mathrm{El}$ asombro de los presentes en la sinagoga se da cuando Jesús dirá: "Hoy se ha cumplido ante ustedes esta profecía" (Lc. 4,21). Por supuesto Él es el nuevo profeta, el Dios vivo. Jesús, ante la realidad de su pueblo no permanece en silencio, $y$, comienza así el gran contraste entre el plan de Dios y las pobres realidades humanas llenas de ambición, donde los intereses personales y de ciertos grupos que ostentan el poder prevalece sobre las verdaderas necesidades del pueblo pobre. Jesús rápidamente se enfrenta con dos poderes: el poder civil y el poder religioso. Los fariseos y los sacerdotes del templo son el blanco de su ira, porque no sirven la causa de los pobres, sino defienden unas leyes muertas y sin sentido que producen pobres y explotados a servicio de los intereses de pocos. Por eso Jesús no calla, y provoca la ira de estos poderosos protegidos por leyes caducas.

El Plan de Dios está lejos de ser el plan del hombre, por eso el mismo Jesús se transforma en Palabra del Dios Vivo. El silencio en Cristo sería como aceptar la maldad del corazón del hombre contra el Plan del Amor de Dios. La vida de Jesús se vuelve una denuncia contra el mal y un anuncio de la verdadera relación que debe existir con el Dios Padre. Un Padre que quiere la realización de sus hijos, en el amor mutuo y en el respeto de la identidad de cada criatura, puesto que estas criaturas son su mejor obra.

Desde Jesús el silencio se hace pecado, porque va contra la voluntad del Padre. Un silencio que se vuelve cómplice de la maldad y del abuso del poder. Por eso Jesús no puede callar y quiere romper los lazos del pecado y liberar al hombre, por tanto no tendrá miedo en decir a los fariseos: "Ustedes, los fariseos, limpian por fuera la copa y el plato, mientras que por dentro están llenos de codicia y de maldad... jay de ustedes, fariseos, que pagan el diezmo de la menta, del 
Luciano Bellinni Fedozzi, sdb.

té y de todas las legumbres, y descuidan la justicia y el amor de Dios!...jay de ustedes, fariseos, que les gusta ocupar el primer puesto en las sinagogas y que los saluden en las plazas!;ay de ustedes que son como sepulcros que no se ven, sobre los que se pisa sin saberlo!...(Lc. 11,39 y ss.)

La voz de Dios, presente en la de Cristo, es una voz que quiere recuperar la dignidad de la persona humana, contra las intrigas y maldades del corazón del hombre que ha perdido de vista su horizonte final, por pequeñas satisfacciones temporales que para obtenerlas tiene que limitar las posibilidades de la mayoría. Por eso Jesús atacará frecuentemente a los ricos, porque por acumular riquezas empobrecen más a los pobres. Jesús cumple con su misión de gritar la verdad sobre el hombre y sobre Dios. Será la Iglesia la que continuará esa misión después de la Resurrección. Muchos primeros cristianos sellarán su fe con el martirio. Pero también la Iglesia en su historia tendrá momentos oscuros, y no ceñidos al profetismo del Evangelio. Lo humano siempre está latente y busca su propia parte, desfigurando así la verdadera imagen del rostro de Cristo. Pero en este camino de luces y sombras la Iglesia, pueblo de Dios ha tenido grandes figuras de santos que la han hecho regresar a su verdadero cauce.

Un gran acontecimiento, en la segunda mitad del siglo pasado, es el Concilio Vaticano II, iniciado en 1962 por el Papa Beato Juan XXIII y culminado en 1965 por el Papa Pablo VI. Personalmente lo definiría como una relectura y actualización de la Buena Noticia de Jesús para el hombre de nuestro tiempo. Quizás un documento nunca bien conocido y adecuadamente puesto en práctica. Sin embargo en él encontramos las más grandes afirmaciones sobre el hombre y su dignidad, el papel de la mujer, la familia, los derechos, la educación de la persona, la iglesia y su compromiso con la sociedad, la vida sacerdotal y religiosa y su papel en la comunidad de creyentes y no creyentes.

El Concilio Vaticano II es ciertamente el compendio más claro del pensamiento de la Iglesia en su papel con el hombre contemporáneo. Y sigue defendiendo, como a lo largo de toda su historia, los derechos del ser humano. En la Gaudium et Spes encontramos: “...(es), necesario que se facilite al hombre todo lo que se necesita para vivir una vida verdaderamente humana, como son el alimento, el vestido, la vivienda, el derecho a la libre elección de estado y a fundar una familia, a la educación, al 
trabajo, a la buena fama, al respeto, a una adecuada información, a obrar de acuerdo con la norma recta de su conciencia, a la protección de la vida privada y a la justa libertad también en materia religiosa" (Gaudium et Spes 26 b)

Y todavía en otro párrafo de la misma Constitución Pastoral encontramos: "... toda forma de discriminación en los derechos fundamentales de las personas, ya sea social o cultural, por motivo de sexo, raza, color, condición social, lengua o religión, debe ser vencida y eliminada por ser contraria al plan divino. En verdad, es lamentable que los derechos fundamentales de la persona no estén todavía protegidos en la forma debida en todas partes". (Gaudium et Spes 29)

Siglos han pasado desde los antiguos profetas, pero ciertas situaciones generales del pueblo no han tenido mayores variaciones. No podemos desconocer los grandes avances de la ciencia y tecnología en nuestro tiempo, pero no podemos afirmar que estos grandes descubrimientos y progresos tecnológicos hayan producido cambios sociales. Más bien constatamos que la brecha entre ricos y pobres es cada vez más grande, los ricos son cada vez más ricos y los pobres cada vez más pobres. Por esta razón la Iglesia Latinoamericana, reflexionando sobre la reali- dad del hombre en el Continente, hace sus grandes encuentros de reflexión: Río de Janeiro (1955); y luego enriquecida por la experiencia del Concilio Vaticano II se reunirá en Medellín (1968), Puebla (1979) y Santo Domingo (1992).

El encuentro que más contribuyó al cambio de la Iglesia en América Latina, fue el de Medellín. Encuentro que obligó a los Obispos, sacerdotes y religiosos a grandes renovaciones pastorales en sus diócesis, confrontándose con situaciones de extrema pobreza del pueblo, oprimido por los malos gobiernos y por toda una época de dictaduras en casi todos los países del Continente. La Iglesia trata de dar voz a los que no la tienen, teniendo que pasar por graves enfrentamientos con los poderes políticos, pagando en muchas circunstancias con sus propias vidas.

Yo diría que el Concilio Vaticano II y para América, Medellín, han sido una auténtica vuelta al Evangelio de Jesús. Este nuevo impulso del Espíritu Santo en nuestro Continente ha producido nuevos mártires. Solamente en las últimas dos décadas del siglo pasado, más de trescientos cristianos, hombres que amaban la justicia, y deseaban se implantara el derecho y el respeto de la dignidad humana, ofrendaron su vida y su sangre para la liberación del pueblos. El que 
Luciano Bellinni Fedozzi, sdb.

más recordamos, es ciertamente Oscar Arnulfo Romero, en San Salvador, pero con él muchos otros, como Cristo, sacrificaron sus vidas por el Amor a Dios en el Hombre concreto. En el Ecuador recordemos Segundo Francisco Guamán (1983), Felipa Pucha y Pedro Cuji en el mismo año, Alejandro Labaca e Inés Arango en 1987. La persecución sufrida durante la dictadura a Monseñor Leonidas Proaño Villalba, por ser el pastor de los indios de nuestro país.

Nuestra realidad actual en América no difiere mucho de la de años atrás. Malos gobiernos, distribución de bienes perversa, falta de empleo, mala educación que se recibe, y por lo mismo incremento de analfabetismo, aumento del fenómeno de la migración, explotación de la niñez y la infancia, disgregación de las familias, poca ingerencia de los padres en la educación de sus hijos, relativismo en la conducta y en los valores culturales y religiosos, moral permisiva, influencia negativa de los medios de comunicación, el mundo globalizado que hace perder la propia identidad, falta de ideales y compromisos de larga duración en nuestros jóvenes...

Nuestro país, rico en tantos productos naturales, en minería, en petróleo, en tantos productos de exportación. Rico en su diversidad geográfica y climática, en sus ríos, valles y montañas; rico en su diversidad étnica y cultural, sin embargo estamos fabricando un mundo de pobres, no porque seamos ociosos, como algunos quieren hacernos creer, sino porque los pocos vivos manipulan las leyes a su favor, y manejan la mayoría de los recursos en su beneficio. Entonces hay que recordar la profecía de Santa Mariana de Jesús, que no serán los volcanes los que destruirán el Ecuador, sino los malos gobiernos, y yo añadiría a los malos ecuatorianos.

Entonces entendemos ¿por qué el silencio es pecado? 